\title{
EFFECTS OF TOURISM-LED URBAN REGENERATION ON THE HISTORICAL PART OF TEHRAN, IRAN
}

\author{
MAJID MANSOUR REZAEI ${ }^{1}$, ALI MOHAMMAD SAADATI $^{2} \&$ HELYA SEHAT $^{3}$ \\ ${ }^{1}$ Urban and Tourism Study Group, Shanbeh Shahr, Tehran, Iran \\ ${ }^{2}$ Mayor of the historical region of Tehran (region12), Iran \\ ${ }^{3}$ University of Tehran, Iran
}

\begin{abstract}
Over the last half-century, the role of tourism all over the world has increased remarkably in cities creating serious competition between cities in attracting more regional, national, and international tourists. Tehran has been the capital of Iran for over 200 years, however its relationship with urban tourism is new and young, with an attractive and audible narrative. For the very reason of this newly created dialogue, Tehran has been chosen to be studied through the lens of three eras: Qajar, Pahlavi, and Islamic Republic. Each era shows a monarchy, which shaped the capital based on a particular set of views, demands, and ideologies. Like most capital cities, Tehran had to change or even mutate at the demand of the different monarchies, and no wonder the city had lost many layers of its heritage and attractions through the urban changes. A major part of the urban changes has taken place in the last century. However, over the last 15 years, urban tourism has developed rapidly in Tehran. This means that tourism-led urban regeneration has successfully reshaped the cityscape, stimulated the renovation of many attractions and neighborhoods especially in the historic part of Tehran. The purpose of this article is to study and analyze urban tourism and its effects in Tehran over the last 15 years. Also, focusing on the historical part of Tehran, the role of urban tourism in regenerating the historical part of Tehran was investigated. The article is prepared for practical purposes. The research method is descriptive-analytical. Since the authors are the leading activists in the field of urban tourism in Tehran, the research is based on observations, conversations, and surveys done in four months (May-August 2020). Ultimately, the article presents the most important programs and projects necessary for the reform and development of urban tourism in the historical part of Tehran.
\end{abstract}

Keywords: tourism-led, urban regeneration, historical part, Tehran.

\section{INTRODUCTION}

In 1786, the Qajars empowered in Iran and introduced Tehran as the capital of the Qajar dynasty, but where was Tehran? A small and somehow, an infamous village located in the north part of the Central Plateau, which was noticed by Shah Tahmasb (the second Safavi king) for military and political purposes 232 years before its capitalization and raised great walls around Tehran.

Qajars chose Tehran as the capital when it was still a city surrounded by its old walls with an area of $4 \mathrm{~km}^{2}$ and a population of fewer than 15,000 people. The capitalization of Tehran drawn attention to the city, causing the development and the creation of new urban spaces, and the development of urban services and equipment. Famous architects and artists were invited to Tehran to build a new capital from all over the country. However, the main development of the capital dates back to the fourth Qajar king Nasser al-Din Shah Qajar. A king who ruled for nearly 50 years and was the first Iranian king to visit Europe at the official invitations.

Nasser al-Din Shah's travels to Europe often coincided with world exhibitions in Vienna, Paris, London, and Brussels. Before these travels, the Isfahan school was the main primary model of Tehran's development. It is a school of Islamic philosophy in arts, also Iranian architecture and urban design that the most prominent examples of which are in the city of Isfahan. However, the result of these travels was extensive changes in all fields especially 
architecture and urban design. From this period on, a new chapter in the architecture of Tehran has begun, and the architects formed a style called Tehran's style by combining the Isfahan school and the European historical styles.

In 1878, as the population of Tehran increased to 150,000 people (approximately 10 times the population of the city), Nasser al-Din Shah commanded to devise a development plan for Tehran. The operators of his command were the professors and students of Dar al-Fonun School (the first high school based on European education), under the management of "Monsieur Bohler". Due to Bohler's efforts, the form of the new plan of Tehran was an octagon based on Renaissance and Baroque patterns, surrounded by ditches with 12 gates, the increase in the area from $4 \mathrm{~km}^{2}$ to $19 \mathrm{~km}^{2}$, and the formation of new public spaces, streets, and markets had changed the cityscape. This area of Tehran forms the old fabric of the city today, which has the values of architecture and urban design as well as being the occurrence place of the most important political and social events of Iranian history. The historic fabric has been the most valuable part of Tehran for decades despite serious changes and widespread destruction.

With the extinction of the Qajar dynasty in 1925 and the empowerment of the Pahlavi dynasty, once again they chose Tehran as the capital. The Pahlavi dynasty tried to erase the remnants of the Qajar dynasty from the city as much as possible, as well as the development of Tehran. During this period, they destroyed the city gates, filled the ditches, changed some of the city's squares, and destroyed several important buildings and sites.

The city of Tehran was expanded to the north, the new residence of the king, and the model of the city of Tehran was undergoing serious changes and from a classic city to a modern one based on motorized transportation. By the return of Iranian architects educated in European schools of architecture and urban design such as the Bauhaus (German art school) and the École des Beaux-Arts, and the government's official invitation of European architects and engineers to cooperate, Tehran quickly moved away from classical patterns and a new Tehran based on modern architectural and urban design patterns was born.

The people Tehran went along with the spirit of modernization. While the development of Tehran and the construction of new neighborhoods with facilities and infrastructures had occurred, some residents of the old part of the city had moved to new parts of the city since the formation of new and attractive cinemas, restaurants, cafes, and public spaces in the newly established parts of the city. The old parts of the city became relatively outdated and boring for some groups of citizens. Moreover, the new parts of the city were places for individual and social behaviors, which were not possible in the old part of the city due to the social structure. Gradually, the area of Tehran increased from $19 \mathrm{~km}^{2}$ to $500 \mathrm{~km}^{2}$, and its population increased from 250,000 to $4,530,000$ people within the 5 decades of the Pahlavi dynasty (1925-1979). The old fabric of the city, as a remnant of the former monarchy, received less attention and development. In other words, the development cycle of the capital led to form a new identity for itself.

There was a revolution in Iran and Tehran was the center of the revolution in 1979. The Pahlavi dynasty gave away to the Islamic Republic. Once again, the new government chose Tehran as the capital of the country. Although there were discussions in the early years of the revolution about relocating the capital, they weren't surefire due to administrative and financial problems. The Islamic Republic tried to change Tehran based on its ideological view and began to erase the symbols of the Pahlavi monarchy. Once again, a new government eliminated a layer from Tehran and omitted a part of the memory of the city and its people.

The old district of Tehran was still not noticed by city managers in the post-revolutionary period, and the development of Tehran was being pursued outside its old district. During this period, the powerful market lobby, which was one of the main influences of the revolution, 
was able to take advantage of the inefficiency of urban management in favor of its economic interests and demands. These districts had valuable neighborhoods, streets, squares, buildings, and spaces that were changed one after another by markets and economic exploitations.

For example, Lalehzar Street, located in the north of the old part of Tehran, was the first street in Tehran designed based on modern European patterns. An attractive street with cinemas, theatres, modern shops, and cafes, which once many intellectuals, writers, poets, journalists, and other artists had come to visit. The powerful forces of the market completely attacked and intervened in this street. The first hotel in Tehran, located in this street, became a warehouse and center for electrical production. Cinemas were closed, some of them changed into passages, and others changed into warehouses. This trend also took place in the old neighborhoods of Tehran, and many of Tehran's old houses with valuable architectural features were turned into warehouses and production workshops.

The historical district of Tehran (Fig. 1), despite the existence of a few historical sites that were accessible to the public, was not recognized as a tourism destination due to problems such as traffic, masculine environment, lack of suitable tourism spaces, insecurity, and lack of support services and facilities. The community and domestic tourists did not consider tourism and other shortcomings. Even foreign tourists who looked at Iran's heritage values with a different perspective have been visiting a common route in Iran for decades. They took a flight to Tehran and went to the south of the country to visit Kashan, Isfahan, Shiraz, and Kerman, and then they return to their own country. For decades, Tehran was not only not seen but also not even introduced. Therefore, the historical district of Tehran should be considered an urban museum that shows signs of Iranian society's efforts to transform from a classical to a modern one.

The first decade of the 21 st century is an important era in the social and cultural development of Iranian society in the post-revolutionary period. The development of cultural spaces and the growth of civil society led to a discourse in the public sphere of Tehran. Making documentaries, holding meetings with architects and urban planners, sociologists,

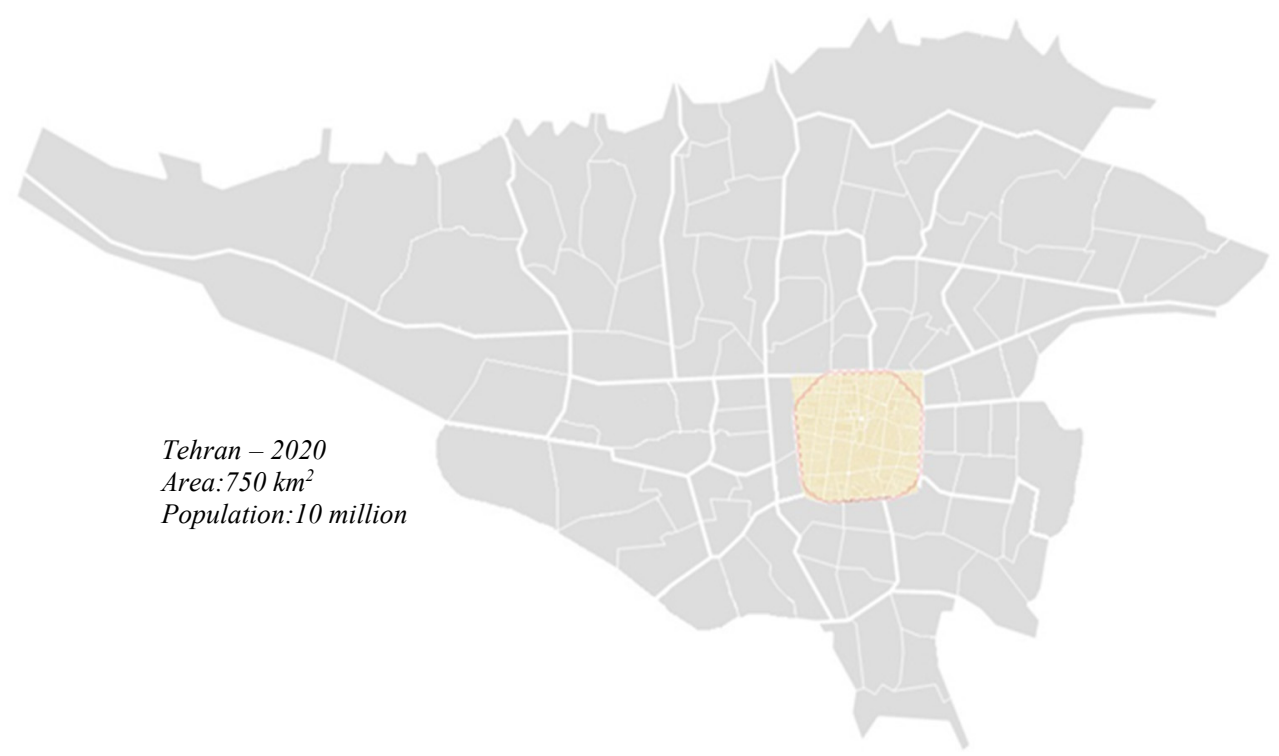

Figure 1: Location of the historical district of Tehran. 
and artists, created an arena to investigate for a range of enthusiasts. Gradually, public magazines and newspapers prepared special letters about reading Tehran. The municipality of the old part of Tehran built several metro stations in the old part of Tehran and began limited measurements to implement action plans in the old part of Tehran. Several educated and interested young people started to tour in Tehran to show the hidden values in the old context of Tehran. Progressively, the private sector built a few restaurants, and cafes and the process of regeneration of the historical district of Tehran began.

\section{TOURISM AND URBAN TOURISM}

The concept of tourism is a complex and dynamic one. From the primary definitions of tourism that was offered in the first decade of the twentieth century until recent definitions it has been changing, so it is not easy to define it straightforwardly. From Guyer Feulner's point of view [1]: tourism is a unique phenomenon at modern times which is dependent on people's increasing need for a change and relaxation, their wish to recognize the beauties of nature, and the belief that nature gives happiness to human. At that time tourism was meant by going to nature. After the Second World War, an affiliation between the definition of tourism and "nature" has decreased, and "places" as a destination much Were noticed, for example, Cohen [2] mentioned that: tourism means visiting a "place" for leisure activities, like a holiday, entertainment, visiting family and friends, sports, resting, and recreation. According to Cohen [2], these places could be anywhere and were not limited to nature. Also, today based on tourist concepts are published by the United Nations World Tourism Organization (UNWTO). Modern tourism encompasses a growing number of new destinations, which are different from an old destination like natural, historical, beach sites and museum. In this regard and according to the European Commission [3], interest in local cultures and urban destination is growing, due to improving levels of education and economic welfare of common people, the desire to try different tastes, familiarize with different cultures, and shop, and because "Sea-Sand-Sun" tourism has considerably lost its popularity [4]. Tourism in cities became important. Tourism previously has developed in historical cities and capitals of states and then began to flourish in other cities by growing up. But in fact, what is urban tourism?

Researchers agree that urban tourism is a complex phenomenon consisting of a variety of tourism activities such as relaxation and entertainment in the city, recreational shopping, participating special arrangements and business meetings, art galleries, concerts, festivals, visiting some attractive places like exhibitions, demonstrations, shows, and museums, visiting kith and kin and relatives [5] but The actual attractions in urban tourism consist of humangenerated attractiveness as well as the activities which are based on historical and cultural attractiveness. According to the UNWTO, Urban Tourism is "a type of tourism activity which takes place in an urban space with its inherent attributes characterized by non-agriculturalbased economy such as administration, manufacturing, trade, and services and by being nodal points of transport. Urban/city destinations offer a broad and heterogeneous range of cultural, architectural, technological, social, and natural experiences and products for leisure and business".

The European Commission [3], defines urban tourism as "the set of tourist resources or activities located in towns and cities and offered to visitors from elsewhere". According to Law [6], Urban Tourism distinguishes between primary and additional elements of a city's tourism resources (Fig. 2). 


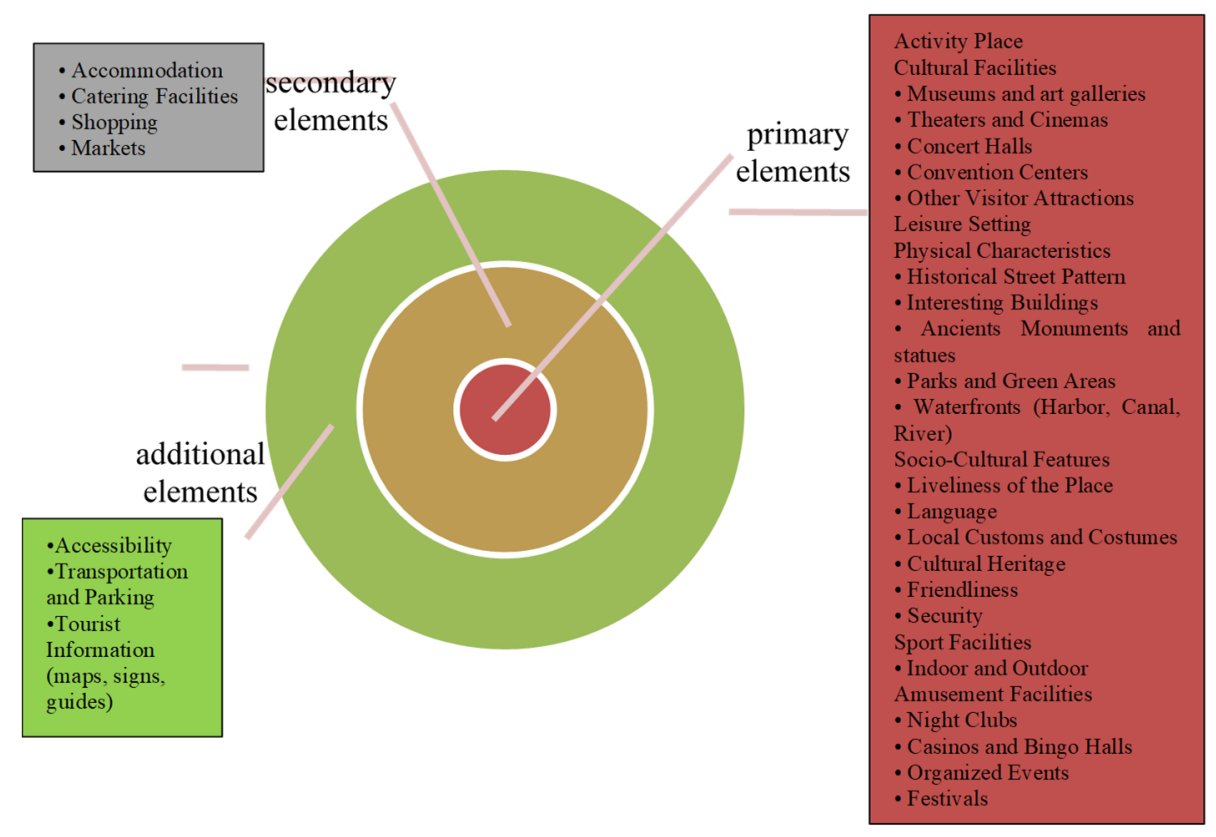

Figure 2: Urban tourism's resources.

\section{URBAN REGENERATION}

Urban regeneration can be traced back to the mid-19th century, to the urban development programs of Baron Haussmann in Paris [7]. But the theoretical definition of this concept dates back to the 1960s in policy programs addressing social deprivation in inner-city areas [8]. Urban regeneration was first formalized in the USA in the 1960s when relocation of marine activities triggered the total abandonment of large territories, which have become harbor derelict lands. Municipalities have often reassigned these empty urban lands to central business types of activities as Boston, Baltimore, and New Orleans. In the 1980s, a second phase was launched, on the London Docklands, and then in Barcelona. Urban regeneration led to the complete transformation of empty lands, through the reconstruction of multi-activity "bits of the city". Later, in the 1990s, urban regeneration was launched in many urban areas, often densely populated, functionally heterogeneous, but facing many urban malfunctions [9]. In a general definition, urban regeneration can be described as follows: "A comprehensive and integrated vision and action which leads to the resolution of urban problems and which seeks to bring about a lasting improvement in the economic, physical, social and environmental condition" [10]. However, although urban regeneration is often regarded as a comprehensive, holistic discipline, encompassing all the aspects mentioned, in practice it is rarely, if ever, truly comprehensive. It should be noted that it is different from urban renewal, urban rehabilitation, and urban (re)development. Urban regeneration, in essence, intends to change the nature of a place by involving the public, private and community and voluntary sectors working together toward a clear single aim: to improve the quality of life for all [11]. Fig. 3 indicates the variety of themes and topics involved in urban regeneration and the multiplicity of interrelated outputs such as Neighborhood strategies, Training and education, Physical improvements, Economic development, and Environmental action. 


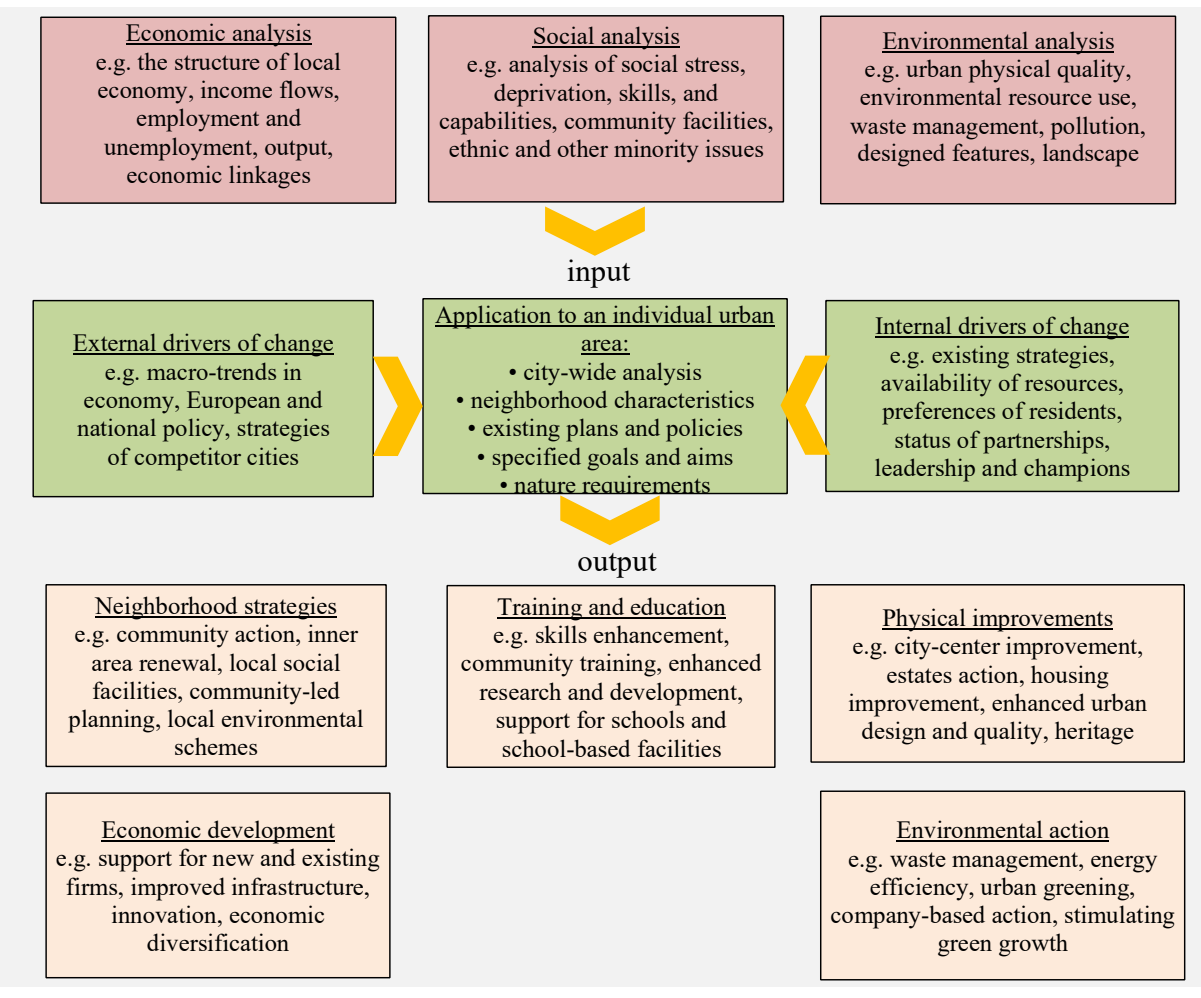

Figure 3: The urban regeneration process. (Source: Roberts, 2000 [10].)

\section{URBAN TOURISM-LED URBAN REGENERATION}

Recently, tourism and urban regeneration gained importance as two activities related to each other. As Swarbrooke [12] observes: "Tourism-based urban regeneration has become a major phenomenon in the past two decades". A lot of researchers highlight the close relationship between tourism and urban regeneration [12]-[14].

Tourism and urban regeneration are two activities that have risen in importance in the last two decades. Tourism is used as an urban regenerative tool as it is perceived to offer several benefits for towns and cities. from academic literature obviously that There is a well-explored connection between urban tourism and urban regeneration, with physical changes in a location (often through flagship developments) being used to boost its competitiveness in attracting businesses and investment and tourism strategies. Law [15] concedes that tourism can assist with physical, economic, and social regeneration, arguing that tourism investment benefits the local community as it involves the development of facilities, activities, the physical environment, and infrastructure. Smart leaders as well as residents who know the potential impacts of tourism can take advantage of this relationship [16].

In recent years, tourism has become one of the main motivations for urban regeneration, particularly in the inner-city areas. Similarly, Swarbrooke and Horner [17] argues that while tourists stimulate the development of services and facilities (e.g. shops, theatres, and infrastructure), these amenities can also be enjoyed by residents. Furthermore, he argues that urban tourism can potentially lead to inward investment from business people who decide to invest in other sectors in the city or relocate their business there. The growth of urban tourism 
in communities that have been badly affected by urban decline can also enhance local pride as residents will feel more positive about their town or city if it is perceived to be a worthwhile place to visit [17]. Tourism can be used to find new uses for derelict buildings and can improve the city's environment. Furthermore, as the restoration of old buildings involves a significant change in purpose (e.g. tourism), infrastructure and transport facilities are also often improved [18]. Zukin [19] highlights the mass appeal of the rehabilitation of heritage buildings for residential usage and tourism development schemes. While the restoration of heritage buildings can attract people back to the city to live, the rehabilitation of buildings for tourism, such as visitor attractions or accommodation, can also attract visitors. Craig-Smith and Fagence [18], argue that expenditure on cultural activity and heritage conservation ultimately pays for itself because of its appeal and use by tourists. Indeed, Craig-Smith and Fagence [18] argue that where possible, historic buildings should be rehabilitated because people are attracted to such buildings as they can relate to the history and historical structures. Tourism is valuable for the restoration, refurbishment, and revitalization of buildings in urban areas. Heritage buildings are commonly rehabilitated for accommodation, commercial storage, retailing, entertainment, and cultural purposes [19].

Tourism can be used to find new uses for derelict buildings and can improve the city's environment. Furthermore, as the restoration of old buildings involves a significant change in purpose (e.g. tourism), infrastructure and transport facilities are also often improved [18].

\section{RESEARCH DESIGN AND APPROACH}

In the first part, based on field observations and in-depth conversations of writers with managers of urban development and tourism in the historical district of Tehran, an attempt was made to answer this basic question:

Has the historical part of Tehran been able to create the necessary elements to become a tourism area? And what are its shortcomings?

In the second part, based on the literature reviewed in the field of urban regeneration, we identified and analyzed the effects of urban tourism on regeneration, focusing on its physical dimension, from the perspective of urban design.

Information presented in this article is the result of observations, conversations, and surveys done in 4 months (May-August 2020).

\section{THE CASE OF TEHRAN - HISTORICAL DISTRICT}

The historical region of Tehran has faced serious economic and social problems for decades due to transformation, high-level migration, crime, the decay of buildings, public spaces and infrastructure systems, and environmental damage, plus the expansion of Tehran and the creation of new neighborhoods and the relocation of old residents to these areas. A significant number of Afghan war migrants have settled in the historical part of Tehran and residents who do not have any attachments to the area and its values. On the other hand, this area includes historical buildings belonging to the post-Renaissance period, which are production workshops and warehouses due to their proximity to the commercial area and the main urban services.

The case study is Tehran's historical part called Naseri's Tehran is a clear example of the opportunity of tourism for regeneration, where urban regeneration has recently taken place for the needs of tourism. Tehran's historical part after a long time that had faced a crisis and has been regaining a new identity for its role in the culture and social system. The historical part has also changed in social terms. It is becoming even more multicultural, which many citizens and tourists want to visit and explore. Today many young people rediscovering their origins and its true greatness with a feeling of pride. To regenerate its territory and economy, Naseri's Tehran has adopted a coherent tourism policy. 
The case study provides evidence to find a compromise between tradition and innovation, between the idea of tourism as a source of identity and social capital, and the culture as an important economic resource for the historical district of cities.

\subsection{Part one: Observation of urban tourism resources}

Although there in the historical part of Tehran has been some tourist attractions for a long time, such as several museums and several palaces, these spaces and places were not very popular for tourists. Tourists who visited these spaces and places had nothing to do with the historical part and quickly left this area. The beginning of the 21 st century was a special period for the historical fabric of Tehran. For the first time, the Municipality closed two street bazaars to cars in this area and carried out urban design projects in the street. The private sector, citizens, and space users welcomed the projects. The Municipality facilitated access to the area by the creation of several metro stations, and the area saw a greater presence of women gradually. The private sector gradually realized the emerging need. The need was growing due to the presence of the new audience in the area. The audience came to the area due to the absolute advantage of the region in offering cheaper goods due to the presence of the grand bazaar of Tehran. The outer edges of Tehran Bazaar, located in the central part of Tehran's historic fabric, gradually changed from general-purpose stores to retail stores and support services for everyday urban life. Also, around 2009, independent groups and individuals organized creative tours in the historical context of Tehran. The private sector gradually realized the emerging need. The need was growing due to the presence of the new audience in the area. The audience came to the area due to the absolute advantage of the region in offering cheaper goods due to the presence of the grand bazaar of Tehran. The outer edges of Tehran Bazaar, located in the central part of Tehran's historic fabric, gradually changed from general-purpose stores to retail stores and support services for everyday urban life. Also, around 2009, independent groups and individuals organized creative tours in the historical context of Tehran. Now you can see new events every day. Tourism information spaces hold various meetings about tourism potentials in this district. Various sectors exploited these potentials with plenary cooperation, now. according to Law [6], urban tourism distinguishes between primary, secondary, and additional elements of urban tourism resources. These elements are observed and recognized by the authors as the activities in developing tourism. from Our observations showed the secondary elements such as accommodation and shopping as well as additional elements such as transportation and tourist information services have developed, but most developments have happened in the primary elements such as historical characteristics of buildings, streetscapes, and neighborhoods, by the emphasis on the local character. Fig. 4 was analyzed and categorized based on urban tourism resources provided by Law in the area.

\subsection{Part two: The observation of physical regeneration}

The important interventions that have taken place in the district have a straightway correlation with tourism. Tourism-led regeneration relying on the potential of the historical part of Tehran has been creating socio-cultural and economic value at the local scale so far. As a result of all these interventions, the historical heart of the city has begun to beat again. According to the authors' observations, repair, renovation, and revitalization of historic monuments and public spaces, with or without land-use change, have played a crucial role in urban tourism development, so most tourists tend to visit these spaces. 


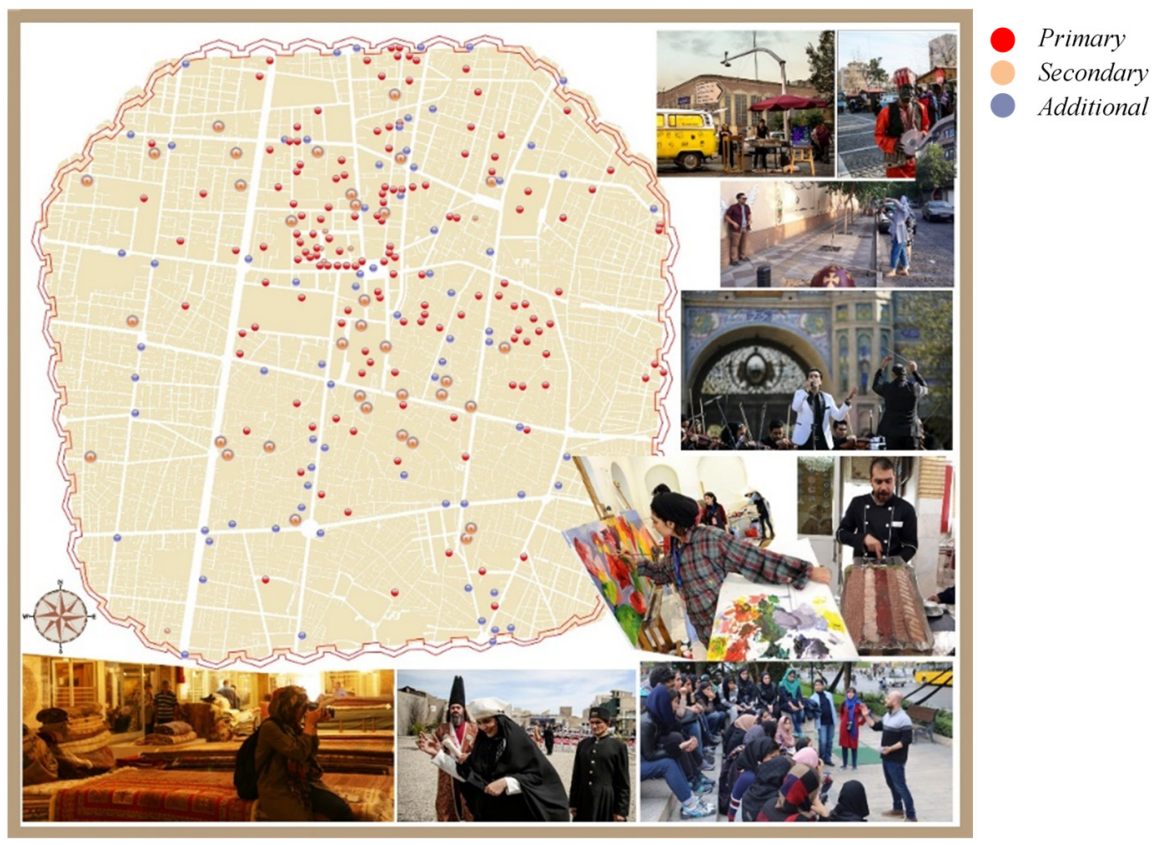

Figure 4: Urban tourism resources created during the last 2 decades in the historical district of Tehran.

The process of urban regeneration in the historical part has caused the regeneration of many areas and buildings both economically and socially with the help of urban tourism. For example, the development of tourism and its effects in recent years have led to the Preservation and revitalization of many old buildings, also the relocation of disturbing and incompatible jobs and activities in some parts of the district. These two projects are mentioned as the evidence for this claim, the "Oudlajan Bazaar" project is the result of transforming a plastic-selling into a handicraft bazaar, and the "Hajiha Passage" Project is also the result of transforming warehouse performance and incompatible activities into a reception, restaurant, and gallery space.

Although many regeneration schemes had relied on significant municipality funding for key infrastructure and tourism facilities, the recent private sector investments in tourism support services have helped the process of regeneration significantly in the historical part of Tehran.

In this regard, the municipality has been able to provide appropriate and attractive options for investors and activists in the field of tourism. By identifying, updating, and completing the database of valuable buildings in the area for the revitalization of historical buildings owned by the municipality, and encouraging the private sector to provide incentives for owners to preserve and revitalize the valuable buildings.

From Peter Roberts's point of view, the variety of themes and topics involved in urban regeneration and the multiplicity of interrelated outputs. This article focused on the physical dimension and showed how most of the interventions relied on the creation of flagship buildings and urban spaces to change the perception of a place. Fig. 5 shows the distribution and diversity of the physical dimensions of urban regeneration to create tourism projects in 


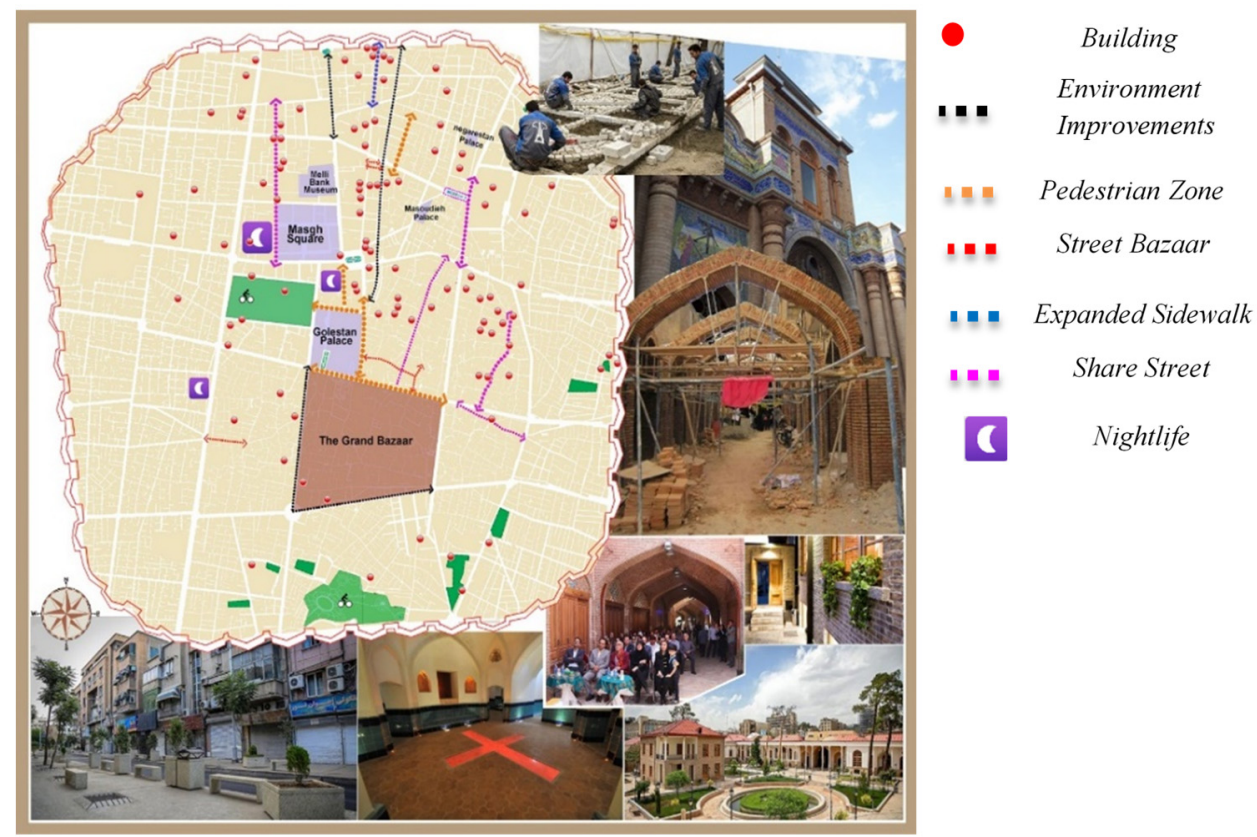

Figure 5: Physical dimensions of urban regeneration during the last two decades in the historical district of Tehran: 43 building restorations, 22 street-environment improvements, and 18 urban street designs.

the district. Although the distribution of these projects is not the same, in addition to improving the physical and urban landscape, these projects have been able to help improve the social and economic dimensions of its areas and neighborhoods.

\section{CONCLUSION}

The primary aim of urban regeneration is to address the complex dynamics of urban areas and their difficulties. Tourism should be introduced as an essential element in urban regeneration. Developing tourism can achieve Neighborhood strategies, Training, and education, Physical improvements, Economic development, Environmental action.

The identification of challenges and opportunities for the city to achieve urban regeneration based on urban tourism can shed light on the nature of policy-making and executive measurements. In the historical part of Tehran, due to the unfavorable quality of space and also the significant destruction of old buildings and structures, the main focus was on the improvement of the spatial qualities, production of the place, revitalization, and regeneration of the buildings based on tourism.

Increasing tourism services and facilities helped to regenerate the historical district, due to Tehran's emphasis on developing urban tourism and the increase in the number of visitors and investment opportunities. Now that the flow of tourism has developed to a considerable extent in the area, it is necessary to consider and plan other sectors of the urban regeneration process.

Tourism-led regeneration in the historical area of Tehran should be supported not only by place-making but also by the socio-economical and cultural conditions of residents of the 
area should be improved. The historical district of Tehran, with its tangible and intangible cultural heritage, has the potential of being a cultural-tourism center. Improvements should be made to improve the social relations and the increase of quality of life as an outcome to get residents involved in the decision-making process. City management has adopted measurements to boost social networks and improve public knowledge, such as holding gatherings with artists, citizens, and private sector investors to learn about the socio-economical benefits of tourism. furthermore, the municipality needs to prepare a comprehensive plan that supports specific tourism plans and emphasizes the area's cultural and historical values.

The following actions can accelerate the development of tourism and urban regeneration:

- Networking and connection of tourism centers and destinations

- Support the private sector in investing in tourism and restoration of historical monuments

- Establishment of tourism information centers

- Improving security in some parts of the region, especially for women and children

- Improving lighting in some sections and streets

- Utilization of digital services to introduce tourism attractions

- Planning and development of branding and marketing of places

- Installation of signboards for places and tourism routes.

\section{REFERENCES}

[1] Bahar, O., cited in Esen, Ș. \& Uyar, H., Competitiveness of Tourism and the Evaluation of Turkey According to the International Tourism Criteria, Bartin University, 2010. www.researchgate.net/profile/Hande_Uyar. Accessed on: 07 Feb. 2015.

[2] Cohen, E., A phenomenology of tourist experiences. SAGE, 13(2), pp. 179-201, 1979.

[3] European Commission, Towards quality urban tourism, Integrated Quality Management (IQM) of urban tourist destinations. European Communities Publications: Brussels, 2000.

[4] Recep, E., Koleva, I., Öztürk, M. \& Arabac, R., Recent Advances in Social Sciences, Cambridge Scholars Publishing, 2019.

[5] Yilmaz, A. \& Gunay, S., Urban tourism and its contribution to economic and image regeneration. International Interdisciplinary Social Inquiry Conference, 2012.

[6] Law, C., Urban Tourism: The Visitor Economy and the Growth of Large Cities, Continuum: London, 2002.

[7] Uysal, U., Urban Tourism in Istanbul: Urban Regeneration, Mega-Events and City Marketing, and Branding, Department of Social Research, Helsinki University, 2015.

[8] Magalhães, C., Urban Regeneration, International Encyclopaedia of Social and Behavioural Science, 2nd ed., Elsevier Publications, 2015.

[9] Priority Actions Programme, Guideline for urban regeneration in the mediterranean region. Regional Activity Centre, 2004.

[10] Roberts, P. \& Skyes, H., Current challenges and future prospects. Urban Regeneration: A Handbook, Sage Publications: London, 2000.

[11] Turok, I., Urban Regeneration: what can be done and what should be avoided? International Urban Regeneration Implementations Symposium, Lütfi Kırdar Exhibition Centre, 2004.

[12] Swarbrooke, J., Sustainable Tourism Management, CABI: Wallingford, UK, 1999.

[13] Law, C.M., Tourism and urban revitalization. East Midlands Geographer, 14, 1991.

[14] Bramwell, B., User satisfaction and product development in urban tourism. Tourism Management, 19(1), 1998. 
[15] Law, C.M., Urban tourism and its contribution to economic regeneration. Urban Studies, 29, 1992.

[16] Evans, G., Measure for measure: Evaluating the evidence of culture's contribution to regeneration. Urban Studies, 42(5/6), pp. 959-983, 2005.

[17] Swarbrooke, J. \& Horner, S., Business Travel and Tourism, Butterworth-Heinemann: Oxford, 2000.

[18] Craig-Smith, S.J. \& Fagence, M., Recreation and Tourism as a Catalyst for Urban Waterfront Redevelopment: An International Survey, Greenwood Publishing Group, 1995.

[19] Zukin, S., The Cultures of Cities, Blackwell: Oxford, 1995. 